\title{
NOTE ON THE ILLÜMINATION REQUIRED FOR THE INSTANTANEOUS COLOUR PHOTOGRAPHY OF THE EYE (LIFE-SIZE)
}

\author{
BY \\ BERNARD ChAVASSE
}

LIVERPOOL

For instantaneous colour photography a single plate process, Autochrome, Paget, Agfa, etc., is necessary. Such plates are necessarily slow. Thus for an open landscape in midday summer sunshine an exposure of one second may be necessary with an aperture f8. Further, owing to the coarseness of the colour graining the nearer life-size the better, especially if the picture is to be used for optical projection.

In order to guard against movement of the eye or of its lids the exposure should not exceed one-twentieth part of a second, which is just less than the lid closure reflex time. (Exner). The exposure factor is therefore $\times 20$. A correction must be applied for the nature of the subject-a coloured object copied life-size. This may be taken as $\times 4$ (Watkins). Moreover, in order to secure adequate depth of focus a long focus lens must be used stopped down to at least f20. This necessitates the further factor of $\times 8$.

It is necessary, therefore, that the illumination of the object be $1 \times 20 \times 4 \times 8=640$ times that provided by the midday summer sun.

Now the light of the sun at the zenith is equivalent to 60,000 candles at a distance of one yard (Poor) which is four candles per square inch of illuminated surface, so that it may be said that for the instantaneous colour photography of the eye an illumination of $640 \times 4=2,560$ candles per square inch is required.

Can this degree of illumination be obtained? An explosive flash of magnesium powder, even when mixed with salts of cerium instead of the more familiar chlorate of potash, just fails to give enough light, even when burned six inches or less from the eye with a glass screen intervening. Nor have I been successful in using it in conjunction with a large condenser, partly perhaps because the light emitted from a sheet of flame does not lend itself well to condensation, and partly perhaps on account of the colour of the glass of the condenser, which cuts off many of the more actinic rays.

The alternative is the electric arc assisted by some optical projection system for the concentration of its rays, and in this connection it may be noticed that on February 15, 1924, at the National Physical Laboratory an "Artisol" lantern (which is a 
lantern provided with a mirror reflecting a solid angle of rays the plane angle of which is 135 degrees, and provided with a thin single condenser) effected, when using only 25 amperes, a screen illumination ( 38 square feet) of 65 candles per square foot, i.e., 2,470 candles. All this light had to pass through a lantern "gate" of about two-thirds of a square inch in area $(24 \mathrm{~mm}$. by $18 \mathrm{~mm}$.) in which therefore the illumination was 3,705 candles per square inch. Since the temperature in the gate is about $700^{\circ}$ Centigrade it would of course be necessary to place the instantaneous shutter in connection with the illuminating source instead of in connection with the photographic apparatus.

Actually, the area to be photographed is greater than that of a circle whose diameter is equal to the diagonal of the gate. But owing to inherent optical defects the sufficiently illuminated area is considerably larger when no hole, slit, or gate is used.

The further step to the colour photography of the fundus oculi would seem to be not an insuperable one, if, as in the Artisol apparatus, condensers are largely or entirely replaced by a converging mirror (by which the chromatic and spherical errors inherent in condensers can be eliminated once and for all), and combined with a hole lamp system (obviously superior to the magnesium flash and condenser system by means of which black and white photographs of the fundus have long been familiar). Such an apparatus is also clearly superior to a hole lamp system with the sun as source, involving a cumbersome apparatus including a siderostat or its equivalent.

Taking the intrinsic brilliancy of the sun when directly overhead as observed through the terrestial atmosphere as 80,000 candles to the square inch it is significant to note that a Pointolite enclosed arc at its maximum intensity (the tungsten bead being then molten) has an intrinsic brilliancy of 60,000 candles to the square inch, and has the advantage over the sun of being not only stationary but also constant. It would seem probable that it will be with a lamp of this type that colour photography of the fundus will be achieved, and it is likely that it will be used in conjunction with a mirror condenser and a hole. 